\title{
Interruption Management in the Intensive Care Unit: Predicting Resumption Times and Assessing Distributed Support
}

\author{
Tobias Grundgeiger and Penelope Sanderson \\ The University of Queensland
}

\author{
Hamish G. MacDougall \\ The University of Sydney
}

\author{
Balasubramanian Venkatesh \\ Princess Alexandra and Wesley Hospitals and The University of Queensland
}

\begin{abstract}
Interruptions are frequent in many work domains. Researchers in health care have started to study interruptions extensively, but their studies usually do not use a theoretically guided approach. Conversely, researchers conducting theoretically rich laboratory studies on interruptions have not usually investigated how effectively their findings account for humans working in complex systems such as intensive care units. In the current study, we use the memory for goals theory and prospective memory theory to investigate which properties of an interruption influence how long it takes nurses to resume interrupted critical care tasks. We collected data with a mobile eye tracker in an intensive care unit and developed multiple regression models to predict resumption times. In $55.8 \%$ of all interruptions there was a finite - and therefore analyzable-resumption lag. For these cases, the main regression model explained 30.9\% (adjusted $\left.R^{2}\right)$ of the variance. Longer interruptions $(\beta=.36, p<.001)$ and changes in physical location due to interruptions $(\beta=.40, p<.001)$ lengthened the resumption lag. We also calculated regression models on subsets of the data to investigate the generality of the above findings across different situations. In a further $37.6 \%$ of all interruptions, nurses used behavioral strategies that greatly diminished or eliminated individual prospective memory demands caused by interruptions, resulting in no analyzable resumption lag. We introduce a descriptive model that accounts for how nurses' behaviors affect the cognitive demand of resuming an interrupted task. Finally, we discuss how the disruptive effects of interruptions in the intensive care unit could be diminished or prevented.
\end{abstract}

Keywords: interruptions, prospective memory, memory for goals, distributed cognition, intensive care

In the present study, we use theoretical models of interruptions and prospective memory to investigate factors that might make it easier or harder for people to return to an interrupted task. The potentially disruptive effects of interruptions on cognition are well recognized. Interruptions have been examined in aviation (e.g., Dismukes, Young, \& Sumwalt, 1998), driving (e.g., Strayer \& Johnston, 2001), human-computer interaction (e.g., Iqbal \& Horvitz, 2007; McFarlane, 2002), and health care (e.g., Chisholm, Collison, Nelson, \& Cordell, 2000; Coiera \& Tombs, 1998; Parker \& Coiera, 2000). In safety-critical domains, interruptions might contribute to errors and accidents. For example, Westbrook,
Woods, Rob, Dunsmuir, and Day (2010b) showed that interruptions increase the chance of medication administration errors.

Although studies have investigated interruptions in applied settings, most studies are descriptive. In contrast, in the present study we have aimed for a theoretically motivated causal account. To our knowledge, in health care only one empirical paper on interruptions appears to have used a theoretically motivated approach (for reviews see Biron, Loiselle, \& Lavoie-Tremblay, 2009; Grundgeiger \& Sanderson, 2009). In a retrospective analysis of findings from a controlled simulator study, Grundgeiger, Liu, Sanderson, Jenkins, and Leane (2008) used insights from prospec-
Tobias Grundgeiger, School of Psychology, The University of Queensland; Penelope Sanderson, Schools of Psychology, ITEE, and Medicine, The University of Queensland; Hamish G. MacDougall, School of Psychology, The University of Sydney; Balasubramanian Venkatesh, Princess Alexandra and Wesley Hospitals, Departments of Intensive Care and School of Medicine, The University of Queensland.

Tobias Grundgeiger is now at Institute for Experimental Psychology, Heinrich-Heine-Universität.

This paper was written while Tobias Grundgeiger held an Endeavour IPRS at The University of Queensland. This project is supported by the National Health and Medical Research Council (NHMRC) Centre of Research Excellence in Patient Safety. The Centre is funded by the Australian Council for Safety and Quality in Health Care and is an NHMRC Centre of Research Excellence. The Safety and Quality Council is a joint initiative of the Australian, State, and Territory Governments. We also acknowledge support from the Australian Research Council Discovery Grant DP0880920 to Sanderson and Venkatesh. Finally, the authors thank the ICU staff of the Princess Alexandra Hospital for supporting the research and Tania Xiao for comments on previous versions of the manuscript. A preliminary analysis on data from four nurses was published in a conference proceedings (Grundgeiger, Sanderson, MacDougall, \& Venkatesh, 2009b) and the distribution of memory demands was published in a conference proceedings (Grundgeiger, Sanderson, MacDougall, \& Venkatesh, 2009a). In addition, a high level summary of the study has been reported in a further conference proceedings (Grundgeiger et al., 2010).

Correspondence concerning this article should be addressed to Tobias Grundgeiger, Institute for Experimental Psychology, Heinrich-Heine-Universität, D-40225, Düsseldorf. E-mail: tobias.grundgeiger@uni-duesseldorf.de 
tive memory studies to explain why some anesthesiologists forgot a task. Moreover, the design of most health care studies does not allow researchers to draw defensible conclusions about the disruptive effects of interruptions. Only three studies provide direct evidence that participants forget planned tasks due to an interruption (Collins, Currie, Patel, Bakken, \& Cimino, 2007; Liu, Grundgeiger, Sanderson, Jenkins, \& Leane, 2009; Westbrook et al., 2010). Most authors base their assumption that interruptions disrupt memory processes on laboratory studies (e.g., Einstein, McDaniel, Williford, Pagan, \& Dismukes, 2003; Monsell, 2003) and infer that similar effects operate in the field.

Laboratory research on interruptions has advanced the development of theoretical models of task interruptions (for a review see Trafton \& Monk, 2007). However, tasks in the laboratory are often unfamiliar, and the discretionary use of supporting artifacts is prevented. So far, laboratory research on interruptions appears to be limited to the study of unaided individual humans solving tasks that are presented via a computer. It is unclear whether, and to what extent, findings from studies of individual humans doing computer-based tasks in the laboratory can account for interruption and resumption processes in field settings.

The first aim of this study was to test whether the above models of individual cognition can be used to study interruptions in the field. We investigated the potential effects of interruptions on intensive care unit nurses, using the memory for goals theory (Altmann \& Trafton, 2002) and prospective memory theory (Dismukes \& Nowinski, 2007). A mobile eye tracker was used to measure the task resumption lag-the time from the end of an interruption to the retrieval of the interrupted primary task (Trafton, Altmann, Brock, \& Mintz, 2003)_and to code information about factors influencing the resumption lag. We developed multiple regression models to predict the resumption lag. The six predictors in the models were factors that-according to the literature - should influence the resumption lag. A key question was how much variance would be captured by those predictors.

The second aim of this study was to address the mismatch between health care interruption studies and laboratory studies in terms of the ostensibly disruptive effects of interruptions. Specifically, why are errors due to interruptions relatively rare in health care even though interruptions have consistently disruptive effects in laboratory studies? The mismatch can be attributed to differences between the environments in which the studies were conducted. In everyday life, individuals can use metacognitive strategies and physical artifacts to help them meet cognitive challenges (Hutchins, 1995a; Neisser, 1976; Suchman, 1987; Zhang \& Norman, 1994). To investigate aided prospective memory tasks, we adopt the approach of distributed cognition (Hutchins, 1995a, 1995b). From the perspective of distributed cognition, cognitive processes are not confined to individuals but instead are distributed across different agents (people, processes, devices) that jointly solve cognitive problems. In health care, distributed cognition has been used to investigate the use of artifacts (Nemeth, Cook, O'Connor, \& Klock, 2004; Xiao, 2005), coordination (Hazlehurst \& McMullen, 2007), and computer-assisted clinical ordering (Horsky, Kaufman, Oppenheim, \& Patel, 2003) and situation awareness (Fioratou, Flin, Glavin, \& Patey, 2010) but it has not been used to investigate interruptions or prospective memory.

In the first section of this paper, we provide an overview of theories and laboratory studies relating to interruptions, introduce distributed cognition, and outline the aims of the current study. In the second and third sections, we report methods and results. In the fourth section, we discuss the results of the regression model, introduce a distributed model of task resumption to accommodate the observed results, discuss limitations and future research, and point out implications for critical care settings.

\section{Laboratory Interruptions Research}

Trafton et al. (2003) have distinguished specific phases of the interruption and resumption process of a task (see Figure 1). For example, consider a nurse preparing a medication for administration (primary task). The telephone rings (distraction) and the nurse eventually stops the medication task and picks up the phone. The time between the distraction and the start of the interrupting task (phone call) is called the interruption lag. The time on the phone represents the interruption length. At the end of the call, the nurse needs to resume preparing the medication. The time between the end of the phone call and resuming the medication task is called the resumption lag. The general interruption and resumption process has been studied with different approaches (for a summary see Trafton \& Monk, 2007). In this section, we present two approaches to studying interruptions: the memory for goals theory and prospective memory theory.

Memory for goals theory. The memory for goals theory (for a detailed description see Altmann \& Trafton, 2002; Trafton et al., 2003) is an activation-based theory and is based on the ACT-R model of cognition (Anderson \& Lebiere, 1998). The theory states that memory always returns the most active goal to central processing and therefore the most active goal in memory is being pursued. If a goal is not attended it decays over time and loses activation. According to the memory for goals theory, the cognitive system uses an item's history (base-level activation) and the current context (associative activation) to overcome decay over time and keep relevant goals active. If the theory is used to investigate interruptions, the relevant goal is the to-be-resumed primary task. The typical dependent variable used is the resumption lag (see Figure 1). Longer resumption lags indicate a less active goal, and therefore a more difficult resumption process, compared to shorter resumption lags.

The memory for goals theory enables detailed predictions about the disruptive properties of interruptions. Because of goal decay, longer interruptions should lead to longer resumption lags, a finding that has been supported by studies (Hodgetts \& Jones, 2006b; Monk, Trafton, \& Boehm-Davis, 2008). Base-level activation can be increased if the participant rehearses the goal during the interruption lag. Trafton et al. (2003) showed that alerting participants to an upcoming interruption and thereby enabling more preparation time caused shorter resumption lags. Furthermore, if the

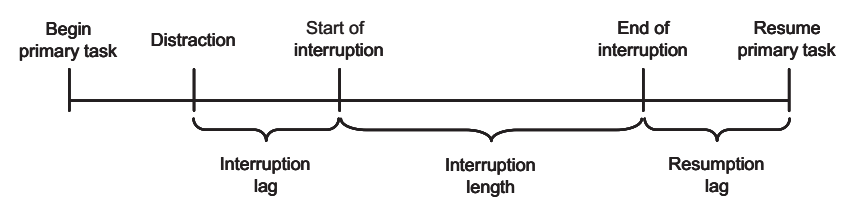

Figure 1. Interruption and resumption processes and associated times (adapted from Trafton et al., 2003). 
participant rehearses the goal during the interruption, then baselevel activation should be increased. This prediction has been supported by multiple experiments using different tasks (Cades, Trafton, Boehm-Davis, \& Monk, 2007; Hodgetts \& Jones, 2006b; Monk, Boehm-Davis, \& Trafton, 2004; Monk et al., 2008). Associative activation is caused by the priming of mental or physical cues. If cues associated with a goal are attended to during the interruption or at the end of the interruption, then associative activation is added to base level activation (Hodgetts \& Jones, 2006a). Furthermore, the memory for goals theory has been used to investigate whether the timing of the interruption with regard to the primary task affects resumption lags. Monk et al. (2004) showed that interruptions in the middle of a task step caused longer resumption lags compared to interruptions after a task step was completed.

Prospective memory theory. Prospective memory is generally referred to as the activity of forming an intention and executing the intention at a future point in time (Marsh, Hicks, \& Landau, 1998). Recently, prospective memory has received considerable attention (Brandimonte, Einstein, \& McDaniel, 1996; Kliegel, McDaniel, \& Einstein, 2008; McDaniel \& Einstein, 2007) and several theoretical accounts have been developed (Einstein \& McDaniel, 1990; McDaniel \& Einstein, 2000; Smith, 2003).

With regard to the interruption and resumption processes in Figure 1, remembering to resume the primary task is the prospective memory task. When a person abandons the primary task, the implicit intention to resume it later is formed (Dodhia \& Dismukes, 2009). The demand of preserving the intention is similar to the demands of the so called delayed-execute prospective memory task. In this task, a intention needs to be delayed because of primary task demands (Einstein et al., 2003). In both paradigms, encoding time is limited and distracted by the interrupting/primary tasks demands, and the time for task resumption is situationally defined by the end of the interrupting/primary task and not by a specific event or time as in other prospective memory paradigms (McDaniel, Einstein, Graham \& Rall, 2004). The typical dependent variable in prospective memory experiments is the frequency with which intentions are remembered.

The associative activation model is an elaboration of the automatic view of prospective memory and was developed in the context of aviation (for a detailed description see Dismukes \& Nowinski, 2007). According to the automatic view of prospective memory, an encoded intention is automatically associated with specific cues. If the cues are encountered at later point in time, a spontaneous retrieval process brings the intention to mind (Einstein \& McDaniel, 1996). According to the associative activation model, automatic processes are always involved in prospective memory tasks, but a person might devote additional strategic processes such as rehearsal or monitoring to execute a future intention. A task is recalled if its representation receives enough activation to pass a threshold. Activation of a task representation is determined by the item's history (baseline activation) and its associations with other memory representations (source activation).

Baseline activation should increase with retrieval and rehearsal of the tasks and it should decrease over time. This prediction has been supported by Dodhia and Dismukes (2009) who showed that memory performance can be improved by longer encoding time or by reminders at the beginning of an interruption (the interruption lag in Figure 1). Source activation should increase when attention is directed at representations that are associated with the intention. This prediction has been supported by studies on cue-task association showing that stronger associations between cues and tasks improve prospective memory performance (Cherry et al., 2001; Nowinski \& Dismukes, 2005). In addition, studies on context change showed worse remembering if the encoding context does not match the retrieval context (Marsh, Hicks, \& Cook, 2006; Nowinski \& Dismukes, 2005).

In summary, laboratory research on interruptions has enhanced our understanding of how individuals with no discretionary environmental support resume interrupted tasks. Although the two theories just described make slightly different predictions regarding what influences task resumption (see Study Aims and Hypothesis), the theories are very similar. In particular, both theories present individual models of the human mind because they assume that cognitive work only happens within individual humans. In many everyday situations, however, humans are acting in an environment that helps them solve cognitive tasks. In the next section, distributed cognition (Hutchins, 1995a, 1995b) is introduced as an approach for studying prospective memory when discretionary environment support such as equipment, notes, and strategies is available. We see in the distributed model an integration of individual models with distributed cognition that can potentially capture the human-environment interaction when people resume interrupted tasks.

\section{Distributed Cognition}

Cognitive science generally takes the individual agent as the unit of analysis for investigation. However, individuals are always in an ecology that influences individual behavior and performance. Hutchins (1995a, 1995b) showed that the principles of cognitive science can be applied when the sociotechnical system is the unit of analysis, such as the cockpit. As is the case for individual cognition, information is represented, transformed, combined, and passed among the agents (human or computational) of a sociotechnical system to accomplish a task. Therefore, cognitive activity is not bound to an individual, such as a nurse, but is distributed over a system such as an intensive care unit (ICU).

Cognition can be distributed in at least three ways (Hollan, Hutchins, \& Kirsh, 2000; Hutchins, 2001). First, cognition can be distributed over time. Actions that have taken place in the past might influence the nature of a task and therefore how it is accomplished in the present. For example, a nurse may receive the order to give a medication in an hour's time. If the nurse places the kit required for medication administration on the table, the likelihood of repeatedly recalling the intention when looking at the kit is increased. Furthermore, the medication might act as a reminder at the time action is needed. Both factors might increase the likelihood of remembering to give the medication.

Second, cognition can be distributed internally and externally with respect to an individual. Individuals can use the environment to decompose tasks into different forms of representations in order to achieve the tasks (Zhang \& Norman, 1994, 1995). Continuing the above example, the nurse and the prescribing doctor initially have a representation of the task in memory. Placing the prepared medication on the bedside bench creates an additional representation of the task in the environment. 
Third, cognition can be socially distributed. Tasks such as navigating a ship, flying an airplane, or treating a critically ill patient involve more than one individual. In the above example, the doctor tells the nurse to give the medication, who in turn might communicate it to another nurse at shift handover or when going for a break.

Critically, if cognition is distributed in any of the above three forms, the task demands imposed on the individual human in the system change (Dobbs \& Reeves, 1996; Hutchins, 1995a; Norman, 1991). Laboratory research on prospective memory focuses mainly on individual memory processes and performance; however, in the field other cognitive processes that support prospective memory cannot be ignored (e.g., Dobbs \& Reeves, 1996; Ellis, 1996; Marsh et al., 1998; McDaniel \& Einstein, 2000; Meacham \& Leiman, 1982). Reports of field research on prospective memory note that people use reminders (e.g., Kvavilashvili \& Fisher, 2007; Marsh et al., 1998; Meacham \& Leiman, 1982), but such reports do not specifically investigate how reminders change the original cognitive demands when the environment is used to remember an intention.

Dobbs and Reeves (1996) suggested six interacting components that are part of prospective remembering: metaknowledge, planning, monitoring, content recall, compliance, and output monitoring. Some of these components offer participants a motivation and means to distribute prospective memory externally into the environment. Because the components will be important for the study reported here and the subsequent model, we outline them in more detail.

Metaknowledge refers to knowledge about prospective memory and it includes general and personal knowledge. General knowledge refers to a person's knowledge about the nature of task demands, strategies that could optimize or impede performance in general, and beliefs about abilities and beliefs of others. Personal knowledge refers to a person's beliefs about their own ability, obstacles to successful performance, and personal utility of performance enhancers. To become effective, knowledge needs to be used in form of a plan. Dobbs and Reeves (1996) call the application of metaknowledge planning. A further component is monitoring which includes monitoring behaviors and monitoring accuracy. Monitoring behavior refers to behavior exhibited while a person waits for the appropriate circumstances to act such as rehearsing an intention. Monitoring accuracy refers to identifying the right moment to act, independently of what the right action is. When the correct circumstances are identified, the individual needs to remember what to do (content recall) and needs to make a decision whether or not to perform a task (compliance). Finally, an individual needs to engage in output monitoring to keep track of whether an intention has been executed or not (Koriat, Benzur, \& Sheffer, 1988).

Dobbs and Reeves (1996) point out that a prospective memory task may include all or only some of the components. For example, in the medication task example, the nurse may anticipate that the medication might be forgotten because the next hour will be busy and the nurse has not administered this medication before. The nurse uses metaknowledge ("I am busy") and personal knowledge ("unfamiliar medication") to plan ("place medication utensils on table"). This action changes monitoring behavior because the nurse is more likely to see the medication kit and check the time. Furthermore, the new task representation might improve monitor- ing accuracy because the nurse more frequently sees the utensils and content recall will be effortless. Finally, the medication on the table helps the nurse monitor the status of the task because a missing medication will now indicate that it has been administered.

To date, researchers have not addressed how nurses react to interruptions in order to prevent detrimental outcomes (Biron et al., 2009). In this paper, distributed cognition is used to explain how behavioral strategies distribute cognition to different agents and help nurses remember to resume interruptions. The six components by Dobbs and Reeves (1996) are used to describe how such distribution changes the nature of prospective memory tasks.

\section{The Current Study}

In this study we combined theoretical constructs from individual models of task resumption with the concept of distributed cognition to investigate the management and effects of interruptions in intensive care nursing. Specifically, we used a mobile eye tracker to collect data about the timing of nurses' activities and constructed multiple regression models with six predictors drawn from the literature to predict resumption lags.

Studying interruptions in the field presents challenges. First, the ability to control what is happening is limited, so experimental contrasts must be constructed around the observed events. A classification schema from health care research (Collins et al., 2007) was adapted to separate distraction-handling strategies that were demanding on prospective memory (interruptions) from strategies that were not demanding (acknowledge or multitask). As described in the Method section, only interruptions create a break in a primary task and so create the prospective memory demand of resuming the interrupted task (Dohdia \& Dismukes, 2009). In our study, each interruption was analyzed for the presence, absence, or quantity of each predictor and the influence of each predictor was tested in the multiple regression models. This approach enables causal conclusions based on "natural manipulations."

Second, in computer-based experiments, the resumption lag is operationalized as the time from the end of an interruption until the first action on the screen. In an ICU, an interruption might require nurses to move to a different location, where they will be at the end of the interruption, and tasks may not involve computers. The mobile eye tracker made it possible to calculate the duration from the end of the interruption until the nurse's first fixation on objects associated with the primary task, and to use the duration as the measure of resumption lag.

\section{Study Aims and Hypotheses}

The first aim was to investigate which predictors from the memory for goals theory and the associative activation model will help us understand the effects of interruptions in intensive care nursing. Based on the literature, the hypotheses for the six predictors in the regression model are as follows:

Finish primary task step. There are higher encoding costs associated with encoding a task resumption point that is in the middle of a task step compared to a resumption point that is in-between task steps (Monk et al., 2004). Higher encoding costs lead to less goal activation (Monk et al., 2004). Therefore the memory for goals theory predicts that midtask interruptions lead to longer resumption lags. In contrast, the association activation 
model predicts no effect of midtask interruptions because the association between the cues and the prospective memory task is created automatically.

Interruption lag. The memory for goals theory and the associative activation model suggest that longer interruption lags (time after the interruption appears but before the interruption is serviced) lead to shorter resumption lags. A longer interruption lag increases goal activation because it provides more opportunity for goal encoding and therefore increases memory performance (Dohdia \& Dismukes, 2009; Hodgetts \& Jones, 2006a; Trafton et al., 2003).

Length of interruption. Both models assume that goals decay over time. Therefore, longer interruptions cause more goal decay and should increase resumption lags (Hodgetts \& Jones, 2006b; Monk et al., 2008).

Fixation on task representation. Both models suggest that cues associated with the primary task that are presented while an individual deals with an interruption will increase goal activation (Hodgetts \& Jones, 2006a). Therefore, longer fixation times on the object that represents the primary task while the individual is serving the interruption should increase goal activation and decrease resumption time.

Distraction during interruption. In the context of the aforementioned delayed-execute paradigm of prospective memory, further interruptions during a delay period worsen prospective memory performance (Einstein et al., 2003; McDaniel et al., 2004). Although neither the memory for goals theory nor the associative activation model specifically predicts this effect, the predictor was included in this study because of its empirical robustness and relevance to the study. It is assumed that additional distractions while serving the interruption will decrease goal activation and therefore lead to longer resumption lags.

Context change. Both models suggest that goal activation is influenced by context cues. If an interrupting task requires the nurse to change location and leave the context in which the goal was encoded, it is expected that resumption lags increase because the contextual cues are missing (Hodgetts \& Jones, 2006a; Marsh et al., 2006; Nowinski \& Dismukes, 2005).

Overall, the memory for goals and associative activation model are very similar theories. Both theories are based on the ACT-R architecture (Anderson \& Lebiere, 1998) of cognition and both consider intentions or goals to be representations in memory with a certain activation (base-level or baseline activation) that decreases over time and that can be increased via different mechanisms (associative or source activation). Therefore the above predictions of the theories are only different for one of the six predictors (finish primary task step) and only this predictor could potentially distinguish the theories. However, the regression model will give an insight into how complete the theories are. If together the theories are comprehensive, one would expect that the regression model to explain a large proportion of the variance in resumption lags.

The second aim of the study was to investigate how nurses might exercise discretion in how they use the environment to increase the likelihood of task resumption. The possible contribution of the environment in helping nurses resuming interrupted tasks was investigated by using distributed cognition (Hutchins, 1995a, 1995b). The hypothesis is that nurses distribute prospective memory processing into the environment and are supported by the environment in resuming a task. If this is the case, nurses should act on or be supported in some ways to overcome prospective memory demands in ways that make task resumption easier, or use artifacts to support one or more components of a prospective memory task as described by Dobbs and Revees (1996).

\section{Method}

\section{Participants}

Ten registered nurses volunteered for the study (four male, six female; average age: 29.9 years; average work experience 7.38 years). To participate, nurses needed to have at least 1 year on-site experience and to wear no glasses (because of the eye tracker). All patients were sedated, ventilated, and needed a high demand of patient care. Written consent was obtained from nursing participants and the patients' next of kin. Participating nurses were blind to research aims and hypotheses and the consent form did not include the words "interruption" or "distraction." The study was approved by the local hospital and university Human Research and Ethics Committees.

\section{Setting}

The study was conducted in a tertiary ICU. In addition to standard medical intensive care equipment such as ventilators, vital sign monitors, and so on (Torpy, Lynm, \& Glass, 2009), each ICU bay was equipped with a computer with a clinical information system. The ICU allocates a dedicated bedside nurse to each patient. In addition, an extra nurse assists $4-6$ bedside nurses. Bedside nurses stay in their patient's bay most of the time. If the bedside nurse needs to leave the patient bay, another nurse relieves so that the patient continues to be monitored.

\section{Equipment}

The researchers developed a lightweight and unobtrusive eye tracking system suitable for use in the ICU (see Figure 2). The system consists of safety glasses with two cameras, a calibration laser, a microphone (total weight of glasses: $75 \mathrm{~g}$ ) and a hip bag with a MPEG recorder, a picture-in-picture video processor, and a battery pack (total weight of bag: $670 \mathrm{~g}$ ). The system recorded (1) the forward field of view of the participant, (2) the right eye of the participant via a dichroic mirror, and (3) ambient audio. To prevent variations in eye tracking with changes in ambient illumination, the right eye was illuminated with an infrared LED, and the eye camera was fitted with an infrared pass filter. Further features included continuous eye splash protection, video and audio mute, recording durations of up to 4 hours per battery charge, and real time point-of-regard display during debriefing.

For calibration, the participant viewed a laser "cross" pattern of lines that subtended a visual angle of $4.1^{\circ}$ horizontally and vertically which was fixed with respect to the head. Putting on the eye tracker and calibrating it took 4 minutes.

The data gathered were processed further using software written in Labview G (National Instruments, Austin, TX). The center of the pupil was determined using a "center-of-mass" algorithm (Moore, Haslwanter, Curthoys, \& Smith, 1996). The vertical and horizontal pupil positions were calculated in Fick coordinates 


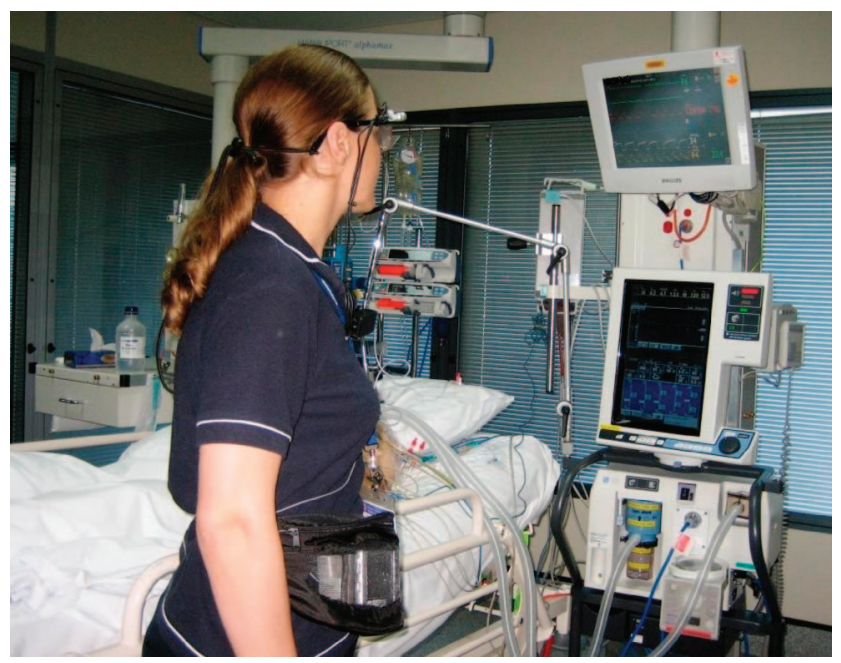

Figure 2. Nurse wearing the mobile eye tracker (glasses with microphone and cameras for scene and eye; on/off switch at shirt collar; recording device and battery in hip bag).

using a spherical model of the eye (Moore et al., 1996), the radius of which was calculated using the calibration procedure in which the subject fixated targets at known gaze angles generated by the head-referenced laser. These algorithms have demonstrated an accuracy and resolution of the order of $0.1^{\circ}$ (Moore et al., 1996). The eye tracking method and equipment of the current study has been compared to the scleral search coil technique and has demonstrated closely comparable eye movement recordings (MacDougall, Weber, McGarvie, Halmagyi, \& Curthoys, 2009), demonstrating the accuracy of the system. The final result after integrating the eye movement data in the field-of-view video was a 30 frame per second video with a red cross on the screen indicating eye fixation location and length (for information and examples of previous use of the system see MacDougall \& Moore, 2005).

In the study, specific predefined areas of interest could not be defined because the objects of interest were constantly changing, depending on the primary task. To test whether objects of interest could be reliably identified, interrater agreement on parts of the eye tracking data was conducted. Two coders watched 2 minutes each of recordings from four nurses and noted the fixated objects (1 min from the first quarter and $1 \mathrm{~min}$ from the last quarter). Objects were meaningful units such as the vital sign monitor, patient limbs, or a medication on the medication desk. Overall, 318 fixations were observed and the coders agreed on 296 (93.08\%) with no difference between the first $(92.91 \%)$ and the last quarter (93.22\%).

\section{Data Collection}

The data were collected individually for each nurse in a threestep process. First, the nurse wore the eye tracker at the start of the morning shift from 7 a.m. until 11 a.m. The eye tracker was taken off during a 20 -min morning tea break at around 9 a.m. The eye tracker was put back on and calibrated after the break. Second, a researcher (T.G.) reviewed the recording and marked points that needed clarification of the clinical work. Third, the nurse and the researcher conducted a video-based debriefing session for clarification of events and for eliciting otherwise unobservable content (Omodei, McLennan, \& Wearing, 2005). At the end, the participant was thanked and given a small gift for participation. Data were collected on weekdays only in order to keep the pattern of events (e.g., regular daily ward rounds and x-ray rounds) as constant as possible between participants.

Advantages of the mobile eye tracker are that it lets researchers collect detailed recordings without having to shadow nurses, as happens with direct observation. The disadvantages were pressure areas caused by the glasses for one nurse and possible reactive effects on behavior given nurses' awareness of being recorded. Although one nurse reported being aware of the glasses, no nurse indicated any behavioral changes due to the glasses.

\section{Analysis}

The analysis was conducted in three steps: classification of distractions and strategies, analysis of interruptions, and analysis of cases with no resumption lag.

Classification of distractions and strategies. We adapted a classification schema used by Collins et al. (2007) by extending the schema to identify the apparent demand on prospective memory of different distraction-handling strategies. A researcher (T.G.) analyzed all distractions and classified them according to the strategy used to handle the distraction. Each distraction resulted in a coded event. The start of a distraction was coded as either the last eye fixation on the current task or the onset of the audio associated with the distraction. The end of a distraction was the last eye fixation on the distracting task.

A distraction was defined as a visual or auditory event that observably captured the attention of the participant and delivered some information. Examples are alarms or coworkers who approached. Nurses handled distractions in any one of three different ways.

- Acknowledging. A nurse could acknowledge the distraction. Acknowledging is defined as a short oral or visual acceptance of the distraction without primary task discontinuity (e.g., brief look at a monitor with an alarm).

- Multitasking. A nurse could multitask the primary and the distracting task. Multitasking is defined as continuous work on both the primary and the distracting task (e.g., answering a doctor's question while setting up an infusion).

- Interrupting. A nurse could interrupt and turn to the distracting task. Interrupting is defined as a "hands off" cessation of the primary task that leads to a discontinuity in the primary task (e.g., stopping medication preparation and turning to an alarming monitor) (Brixey et al., 2007). Critically, only interruptions cause a break in the primary task and therefore require the nurse to form an implicit intention to return to the primary task (Dismukes, 2008; Dodhia \& Dismukes, 2009).

Intrarater and interrater agreement of the coding of distraction handling strategies was assessed by recoding $20 \%$ of the video sampled from four different nurses. Following Bakeman and Gottman's (1997) recommendations for assessing coding agreement for data with timing onsets and offsets, agreement required the coder to identify the same distraction handling strategy within time intervals of $1 \mathrm{~s}$. This resulted in a Cohen's Kappa of 0.90 for intrarater agreement and of 0.77 for interrater agreement. A further 
recoding of different $20 \%$ of the data, this time with predetermined time units requiring the coding of the distraction handling strategy only, resulted in a Cohen's Kappa of 0.92 for intrarater agreement and 0.88 for interrater agreement.

Analysis of interruptions. The resumption lag was measured for each coded interruption. The resumption lag was operationalized as the time from the last eye fixation on the interrupting task to the first eye fixation on the objects associated with the interrupted primary task. A common minimum fixation duration in the literature is $200 \mathrm{~ms}$ (Salthouse \& Ellis, 1980). In this study, an object was considered to be fixated if the fixation lasted for a minimum of four frames. With a frame rate of $30 \mathrm{~Hz}$, the best indication of a $200 \mathrm{~ms}$ fixation is four frames $(4 \times 33.3 \mathrm{~ms}=132$ $\mathrm{ms}$ ) because the previous and following frame will show motion blur because the eye was moving during some part of the light sensitive time. Critically, in all cases included in the model, the initial fixation at the end of the interruption was followed by an action on the primary task.

The following measures were coded for each interruption:

- Finish primary task step (binary value: yes if nurse finishes step such as entering value in electronic patient record or changing a vital sign alarm limit before attending interruption, otherwise no)

- Interruption lag (time from start of distraction to last fixations on primary task in seconds)

- Length of the interruption (time from last fixation on primary task to last fixation on interrupting task in seconds)

- Whether the object associated with interrupted task was looked at during the interruption (fixation time in seconds)

- Whether there were further distractions while attending to the interruption (binary value: yes or no)

- Context change (binary value: yes, if the nurse leaves the current location and walks for at least $1 \mathrm{~m}$, otherwise no). In this study, "context change" is used to describe a broad physical change, as in episodic memory studies (Tulving \& Thomson, 1973 ) and in $85 \%$ of the cases the nurse moved more than $4 \mathrm{~m}$.

Before the multiple regression model was calculated, several issues were considered. First, because the observed interruptions were nested within nurses, not all of the data points are independent of each other. A hierarchical linear regression using HLM 6.0 (Raudenbush \& Bryk, 2002) was calculated to test effects of differences between individual nurses. The result showed that only $0.02 \%(p>.05)$ of the variance came from differences between nurses. We therefore switched to a linear regression model. Second, because reaction time data are generally not normally distributed but instead are gamma distributed, the analysis was started with a generalized linear model. Third, a general linear model with ln-transformed independent variable was calculated which produced the same result as the generalized linear model. Because general linear models are easier to explain and more common in the literature, we report the results of the general linear model. Excluding univariate or multivariate outliers did not change the pattern of results.

Analysis of cases with no resumption lag. We analyzed qualitatively the cases in which a calculation of the resumption lag was not possible for various reasons, such as the participant's use of a strategy that eliminated the prospective memory demands or a primary task temporarily being forgotten. In addition, qualitative results were analyzed for general strategies that could influence task resumptions.

\section{Results}

Overall, 30 hours and 27 minutes of video were recorded. For one nurse, a recording problem resulted in recording without eye tracking. Therefore, the quantitative results are based on nine nurses ( 27 hours and 24 min of video). In total, 570 (20.8 per hour) distractions were coded. These include 239 (41.9\%, 8.7/hour) acknowledgments, 150 (26.3\%, 5.5/hour) multitasking episodes, and $181(31.8 \%, 6.6 /$ hour $)$ interruptions. The breakdown for each participating nurse can be found in Table 1 .

The analysis reveals that $55.8 \%$ of all interruptions observed could be included in the regression model. However, eight cases were excluded from the model because the participant walked back to the primary task before actually looking at the associated object, which artificially increases the resumption lag. In $37.6 \%$ of the interruptions, nurses used behavioral strategies that made it impossible to calculate a resumption lag, either because the task was finished before the nurse attended the interruption, the resumption lag was zero because the nurse was holding a task artifact in the hand, or the interpretation of the resumption lag would have been not meaningful for the instances when a reminder was used. In the remaining $6.6 \%$ of the interruptions, nurses either did not return to the task, forgot temporarily about the task, task resumption was prevented by another interruption, or resumption was not necessary due to a changed situation. The frequencies of the observed interrupted primary tasks and the source of the interruptions based on the above classification are represented in Table 2.

\section{Resumption Lag Linear Regression Models}

In order to estimate and test the influence of each of the six predictors on the resumption lag, we calculated a linear regression model. The model explained $30.9 \%$ of the variance (adjusted $R^{2}=$ $.309), F(6,86)=7.859, p<.001$. The predictor length of interruption $\left(\beta=.36, p<.001, s r^{2}=.329\right)$ had a significant positive effect on resumption lags. Longer interruptions result in longer resumption times. The predictor context change $(\beta=.40$, $\left.p<.001, s r^{2}=.339\right)$ also had a significant positive effect on the resumption lags. Physical context changes due to interruptions resulted in longer resumption times. The predictors finish primary task step $(\beta=-.10, p=.290)$, interruption lag $(\beta=-.04, p=$ $.650)$, distractions during interruptions $(\beta=-.04, p=.662)$, and fixation on task representation $(\beta=-.01, p=.943)$ had no influence on resumption lags. The average resumption lag was 1.073 seconds $(S D=1.178$, Min-Max $=0.092-6.674$ ). In addition, the hierarchical linear regression reported in the method section showed that there was no effect of individual nurses on the resumption times. Because nurses and patients were confounded in the study, we can also rule out a possible effect of the patients' condition on the resumption lag. Table 3 summarizes the results of the linear regression model and provides further descriptive statistics.

To investigate further the possibility that the pattern of results might depend on the interrupting source, we calculated additional two regression models that included different subsets of the data. If a staff member was the source of interruption, the model was significant [adjusted $R^{2}=.296, F(6,44)=4.499, p<.001$ ] with the predictors length of interruption and context change both having a significantly positive effect on the interruption lag. If 
equipment was the source of interruption, with $94.9 \%$ of such cases coming from equipment alarms, the model was significant [adjusted $R^{2}=.256, F(6,32)=3.163, p<.05$ ] with only the significant predictor context change having a positive effect on the interruption lag. Table 4 summarizes the models for the interruption sources in detail.

We further investigated the whether the effect of the predictors change depending on the nature of the interrupted primary task. If only interrupted documentation tasks were included, the model was significant [adjusted $R^{2}=.372, F(6,33)=4.850, p<.001$ ] with the predictors length of interruption and context change having a significantly positive effect and the predictor finish primary task step having a significant negative effect on the resumption lag. If the interrupted primary task was not a documentation task (i.e., it was patient related such as patient assessment or patient care, medication related such as preparation or administration, safety check, or "other" such as clean up or conversation) the model was significant [adjusted $R^{2}=.272, F(6,46)=4.236, p<$ $.05]$ with the predictors length of interruption and context change both having a significantly positive effect on the interruption lag. Table 5 summarizes the models for interrupted primary task in detail.

\section{Behavioral Strategies}

In $37.6 \%$ of all interruptions, nurses used a behavioral strategy to reduce or avoid individual prospective memory demands. First, nurses decided to finish primary tasks before attending to the interrupting task (34 cases, 18.8\% of all interruptions). Second, nurses held, or continued to hold, artifacts such as syringes, cables, equipment for blood samples, or blood gas analysis result sheets in their hands while attending to the interrupting task (31 cases, $17.1 \%$ of all interruptions). The artifacts were always part of the primary task that needed to be resumed at the end of the interruption. In one instance, the artifact was an alarm of an infusion pump related to the primary task that continued while the nurse was interrupted. Third, nurses placed reminders in an obvious position to help them resume the interrupted primary task later, such as putting utensils to take a blood sample on the medication desk (three cases, $1.7 \%$ of all interruptions). Although only three instances of this strategy in relation to interruptions were observed, the strategy was more often used generally to remember future intentions.

To investigate a possible influence of interruption length on behavior, we calculated a Kruskal-Wallis test (because of violated analysis of variance assumptions). The test, which was corrected for tied ranks, showed no significant difference $[\chi(2, N=166)=$ $5.780, p=.056]$ in interruption length between cases included in the overall regression model (mean rank $=87.94$ ), cases of holding an artifact (mean rank $=64.79$ ) and cases of finished tasks (mean rank $=87.37)$. Furthermore, we investigated possible associations between the source of the interruption or the interrupted primary task and the reported behaviors ("regression," "finish the task," and "holding an artifact," in Table 2), however, we did not conduct statistical tests because expected frequencies below 5 in most cells. Nonetheless the table suggests that nurses remembered documentation tasks more frequently than expected without applying a behavioral strategy and less frequently by holding an artifact. The cases in the remaining category "Other" including 


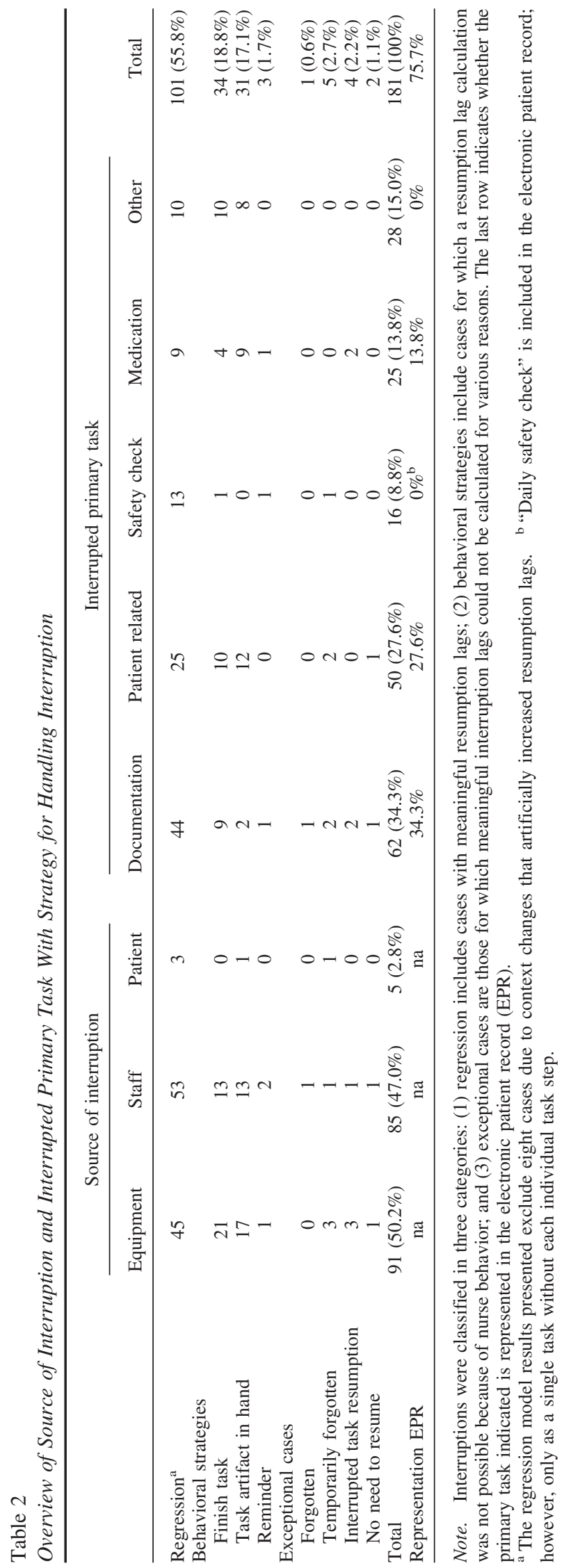

cleaning up and conversations were more frequently finished by nurses before attending an interruption than expected. Finally, if medication tasks or cleaning up tasks were interrupted, a task artifact was held in the hand while serving the interruption more frequently than expected.

General strategies can also remind nurses about forgotten interrupted tasks. They include scanning the top of the bed area while washing hands (five nurses at beds with no sink, therefore scanning not possible; four nurses on average 1.4 scans/hour), looking at places where artifacts are generally placed (all nurses; not quantified but numerous times during recording), accessing the clinical information system (all nurses; average frequencies: worklist 1.3 times/hour; medication orders 1.0 times/hour; observation sheet 1.5 times/hour; nursing notes 0.5 times/hour), and writing paper notes (three nurses). Nurses also reported the four general strategies during the debriefing session.

\section{Management of Exceptional Cases}

In $6.6 \%$ (12 cases) of all interruptions, it was not possible to calculate the resumption lag for several reasons. First, in one instance the interrupted task was not resumed at all $(0.6 \%$ of all interruptions). Second, in five cases nurses temporarily forgot to resume the interrupted task (2.7\% of all interruptions). In these cases, the nurses performed another task after the interruption ended and resumed the unfinished primary task at a much later time (on average 9:57 minutes later). With regard to the six predictors, these five cases shared the features that the average interruption was very long (88.66 s; Min-Max $=19.9-561.7 \mathrm{~s}$ ) compared to the average length of interruptions in the model (44.60 s) and that there was always a context change. Third, in four cases the nurse was about to resume the interrupted task, but was interrupted again (2.2\% of all interruptions). Fourth, in two cases the interrupted task changed the situation so that resuming the interrupted task became unnecessary (1.1\% of all interruptions). In the above cases, calculating the resumption lag either was not possible or the resumption lag would have been not meaningful.

\section{Discussion}

The results show that theories based in individual cognition explained a significant proportion of the variance of the observed resumption lags in the main model. However, only a little more than half the interruptions caused resumption lags, only two of the six predictors were significant, and only one third of the variance was explained. In addition, the regression models on subsets of the data show that-depending on interruption source and interrupted primary tasks-some predictors were significant in one subset but not in another. Furthermore, the analysis of nurses' behavioral strategies shows that nurses' behavior eased or even prevented the memory demands of task resumption. We will discuss the regression models, which are the models of the unaided individual ("the individual model"), before introducing a broader descriptive model that combines individual cognitive processes with the distributed processes observed ("the distributed model").

\section{The Individual Model}

The individual model of task resumption addresses cases in which the resumption of a task depends on the individual nurse. In 
Table 3

Result of the Multiple Linear Regression Predicting Resumption Lags of Interruptions

\begin{tabular}{|c|c|c|c|c|c|c|}
\hline & Mean $(S D)$ & Min-Max & B & $S E \mathrm{~B}$ & $\beta$ & $p$ \\
\hline Constant & & & -.43 & .07 & & .000 \\
\hline Finish primary task step (yes $=1$ ) & $0.41(0.49)$ & - & -.08 & .08 & -.10 & .290 \\
\hline Interruption lag (seconds) & $5.96(11.23)$ & $0-60.89$ & .00 & .00 & -.04 & .650 \\
\hline Length of interruption (seconds) & $44.60(51.74)$ & $3.2-319.12$ & .00 & .00 & .36 & .000 \\
\hline Context change $(y e s=1)$ & $0.58(0.50)$ & - & .33 & .08 & .40 & .000 \\
\hline Fixation on task representation (seconds) & $0.55(1.59)$ & $0-8.11$ & .00 & .02 & -.01 & .943 \\
\hline Distractions during interruption (yes $=1$ ) & $0.13(0.34)$ & - & -.05 & .11 & -.04 & .662 \\
\hline
\end{tabular}

Note. $\quad N=93$ interruptions. $R_{2}=.354$. Average resumption lag $=1.073$ seconds. Significance level $p<.05$.

all cases, the change of context had a significant effect on resumption times. The context change in the current study may have changed environmental cues, which in turn may have triggered retrieval of task demands other than the to-be resumed task, causing longer resumption times (Altmann \& Trafton, 2002; Dismukes \& Nowinski, 2007).

The length of the interruption lengthened the resumption lag in all regression models but not if the interrupting source was simply equipment. An obvious difference between interruptions by staff compared to interruptions by equipment is that all the former involved immediate verbal processing. Interruptions involving verbal processing may have led to worse encoding of the intention to resume (McDaniel, Einstein, Stout, \& Morgan, 2003). Therefore there may have been no decay of activation because base-level activation was already very low. Another potential explanation is that if no conversation is required as in the case for equipment interruptions, the phonological loop might engage in subliminal rehearsal that prevents memory decay from happening.

The predictor finish primary task step led to significantly shorter resumption times only if the interrupted ongoing task was a documentation task (all documentation tasks were computer based). This result replicates previous findings (Monk et al., 2004). How- ever, we found that the resumption lag after an interrupted manual task (e.g., patient assessment, patient care, medication related, safety checks, cleaning up, talking) did not get shorter if the nurse finished a primary task step before attending the interruption. Monk et al. (2004) explain that it is beneficial to finish a task step because of lower resource demands of encoding goals between task steps compared to midtask steps. The current results indicate that such differences in encoding demand might be specifically pronounced for computer-based task, but not for manual tasks.

The predictors interruption lag and fixation on task representation had no influence on resumption lag in any of the calculated regression models. In laboratory studies, a longer time at the beginning of the interruption and the availability of cues or task representations during the interruption both resulted in shorter resumption lags or better prospective memory performance (Dodhia \& Dismukes, 2009; Hodgetts \& Jones, 2006a). In the field, however, nurses may not be able to use the extra encoding and rehearsal time efficiently because they usually need to divide attention immediately to check on the distraction, which compromises intention encoding (Einstein, Smith, McDaniel, \& Shaw, 1997; McGann, Ellis, \& Milne, 2002). Furthermore, questionnaire and diary studies on prospective memory in everyday life indicate

Table 4

Results of the Multiple Linear Regressions Predicting Resumption Lags of Interruptions Based on Source of Interruption

\begin{tabular}{|c|c|c|c|c|c|c|c|c|c|c|c|c|}
\hline & \multicolumn{6}{|c|}{ Interruption source: Staff $(n=51)$} & \multicolumn{6}{|c|}{ Interruption source: Equipment $(n=39)$} \\
\hline & Mean $(S D)$ & Min-Max & $\mathrm{B}$ & $S E \mathrm{~B}$ & $\beta$ & $p$ & Mean $(S D)$ & Min-Max & B & $S E \mathrm{~B}$ & $\beta$ & $p$ \\
\hline Constant & - & - & -0.47 & 0.08 & - & 0.000 & - & - & -0.38 & 0.15 & - & 0.015 \\
\hline $\begin{array}{l}\text { Finish primary task } \\
\text { step (yes = 1) } \\
\text { Interruption lag }\end{array}$ & $0.35(0.48)$ & - & -0.06 & 0.11 & -0.07 & 0.593 & $0.46(0.51)$ & - & -0.18 & 0.14 & -0.21 & 0.182 \\
\hline $\begin{array}{l}\text { Interruption lag } \\
\text { (seconds) }\end{array}$ & $3.27(5.64)$ & $0-30.72$ & 0.01 & 0.01 & 0.19 & 0.158 & $9.78(15.38)$ & $0-60.89$ & 0.00 & 0.00 & -0.17 & 0.285 \\
\hline $\begin{array}{l}\text { Length of } \\
\text { interruption } \\
\text { (seconds) }\end{array}$ & $40.32(51.81)$ & $3.20-319.12$ & 0.00 & 0.00 & 0.38 & 0.006 & $49.61(52.41)$ & $3.72-196.65$ & 0.00 & 0.00 & 0.23 & 0.210 \\
\hline $\begin{array}{l}\text { Context change } \\
\quad(\text { yes }=1)\end{array}$ & $0.43(0.50)$ & - & 0.26 & 0.11 & 0.33 & 0.025 & $0.77(0.43)$ & - & 0.42 & 0.16 & 0.40 & 0.014 \\
\hline $\begin{array}{l}\text { Fixation on task } \\
\text { representation } \\
\text { (seconds) }\end{array}$ & $0.87(2.08)$ & $0-8.12$ & 0.00 & 0.03 & 0.00 & 0.972 & $0.16(0.43)$ & $0-2.06$ & -0.02 & 0.15 & -0.02 & 0.909 \\
\hline $\begin{array}{l}\text { Distractions during } \\
\text { interruption } \\
(\text { yes }=1)\end{array}$ & $0.12(0.33)$ & - & -0.07 & 0.15 & -0.06 & 0.632 & $0.13(0.34)$ & - & 0.09 & 0.22 & 0.06 & 0.704 \\
\hline
\end{tabular}

Note. $\quad N=90$ interruptions. Patients excluded, $n=3 \cdot R^{2}=.380$ for staff model, $R^{2}=.372$ for equipment model. Average resumption lag: Staff interruption $=0.917$. $(S D=1.133)$ seconds; equipment interruption $=1.277(S D=1.261)$ seconds. Significance level, $p<.05$. 
Table 5

Results of the Multiple Linear Regressions Predicting Resumption Lags of Interruptions Based on Interrupted Primary Task

\begin{tabular}{|c|c|c|c|c|c|c|c|c|c|c|c|c|}
\hline & \multicolumn{6}{|c|}{ Interrupted primary task: Documentation $(n=40)$} & \multicolumn{6}{|c|}{ Interrupted primary task: Other than documentation $(n=53)$} \\
\hline & Mean $(S D)$ & Min-Max & B & $S E \mathrm{~B}$ & $\beta$ & $p$ & Mean $(S D)$ & Min-Max & $\mathrm{B}$ & $S E \mathrm{~B}$ & $\beta$ & $p$ \\
\hline Constant & - & - & -0.57 & 0.11 & - & 0 & - & - & -0.42 & 0.09 & - & 0 \\
\hline $\begin{array}{l}\text { Finish primary task } \\
\text { step (yes = 1) }\end{array}$ & $0.33(0.47)$ & - & -0.3 & 0.14 & -0.33 & 0.039 & $0.47(0.50)$ & - & -0.01 & 0.1 & -0.02 & 0.89 \\
\hline $\begin{array}{l}\text { Interruption lag } \\
\text { (seconds) } \\
\text { Length of }\end{array}$ & $5.47(11.68)$ & $0-60.89$ & 0 & 0.01 & 0.04 & 0.791 & $6.34(10.97)$ & $0-56.28$ & 0 & 0 & -0.09 & 0.475 \\
\hline $\begin{array}{l}\text { interruption } \\
\text { (seconds) }\end{array}$ & $37.90(32.96)$ & $3.20-169.00$ & 0 & 0 & 0.37 & 0.013 & $49.65(62.14)$ & $3.72-319.12$ & 0 & 0 & 0.43 & 0.003 \\
\hline $\begin{array}{l}\text { Context change } \\
(\text { yes }=1)\end{array}$ & $0.60(0.47)$ & - & 0.51 & 0.15 & 0.59 & 0.001 & $0.57(0.50)$ & - & 0.26 & 0.11 & 0.32 & 0.023 \\
\hline $\begin{array}{l}\text { Fixation on task } \\
\text { representation } \\
\text { (seconds) }\end{array}$ & $0.89(2.24)$ & $0-8.12$ & 0.01 & 0.03 & 0.08 & 0.626 & $0.30(0.78)$ & $0-4.19$ & 0.03 & 0.07 & 0.05 & 0.674 \\
\hline $\begin{array}{l}\text { Distractions during } \\
\text { interruption } \\
\text { (yes }=1)\end{array}$ & $0.15(0.62)$ & - & 0.05 & 0.17 & 0.04 & 0.773 & $0.11(0.32)$ & - & -0.08 & 0.16 & -0.06 & 0.625 \\
\hline
\end{tabular}

Note. $\quad N=93$ interruptions. $R^{2}=.469$ for documentation model, $R^{2}=.356$ for other than documentation model. Average resumption lag: for documentation task $=1.131(S D=1.266)$ seconds; for other than documentation (i.e., patient-related, safety check, medication, other $)=1.029(S D=$ 1.117) seconds. Significance level $p<.05$.

that having the time to encode and rehearse does not necessarily mean that an individual will make the effort to do so (Einstein \& McDaniel, 2007; Kvavilashvili \& Fisher, 2007). It is even more unlikely that individuals in domains such as health care and aviation rehearse intentions, because of primary task demands and the multiple intentions that need to be executed (Dismukes \& Nowinski, 2007).

The predictor distraction during interruption had no effect on task resumption times. Research on prospective memory has shown that being interrupted while holding a delayed intention worsens memory performance compared with when there is no interruption (Einstein et al., 2003; McDaniel et al., 2004). Despite being a very sensitive measure in other contexts, the predictor had no effect. The conclusion is limited, however, by the low frequency of distractions during interruptions.

In summary, both the memory for goals (Altman \& Trafton, 2002) and the associative activation model (Dismukes \& Nowinski, 2007) can explain parts of the results (interruption length, context change, and distractions during interruptions). The memory for goals model can cope better with the absence of activation increasing effects (interruption lag, fixation on task representation) because these predictors should only have an effect if the nurse decides to rehearse the intention, whereas the associative activation model assumes an automatic increase of activation. Furthermore, the memory for goals theory predicted an effect for finish primary task step, which was present for the computer-based documentation tasks. In contrast, the associative activation model did not predict an effect of finish primary task step at all.

Overall, the memory for goals theory can explain the pattern of results better than the associative activation model. However, the results show that only $55.8 \%$ of all interruptions were analyzable by one or both models and could be entered into the regression model. We suggest a distributed model as an extension to the individual model to account for all of the observed interruptions.
Furthermore, the regression model explained only $30.9 \%$ of the variance in the analyzable interruptions. This suggests that the regression model-its factors based on the results of laboratory studies - is missing factors that contribute to task resumption in the ICU environment. We discuss possible factors in the Limitations and Future research sections.

\section{The Distributed Model}

The distributed model extends the individual model in a way that accounts for the findings regarding behavioral strategies in the current study (see also Figure 3). Behavioral strategies and environmental support both influence and change the memory demands for the individual nurse. The distributed model distinguishes six phases of the interruption and resumption process that are described below.

Phase (1) - Distraction management. In this phase, the nurse decides to let the primary task be interrupted or not (acknowledge or multitask). If the task is not interrupted, $(68.3 \%$ of all distractions), there is no prospective memory demand to resume an interrupted task. Similarly, if a nurse accepts the interruption but the primary task is finished before attending to the interruption, there is no prospective memory demand (6.0\% of all distractions). When the primary task was a conversation, nurses chose more frequently to finish it, possibly because the conversation partner would otherwise leave and not be available when the interruption ended. In addition, there was no association between the actual length of the interruption and the decision to finish the primary task before attending the interruption. Finally, if the nurse accepts the interruption the prospective memory task "resuming the interrupted task" is created ( $25.7 \%$ of all distractions).

Phase (2) - Interruption lag. If the distraction management strategy results in a prospective memory task, the nurse forms an implicit intention to resume the task which is represented in the 


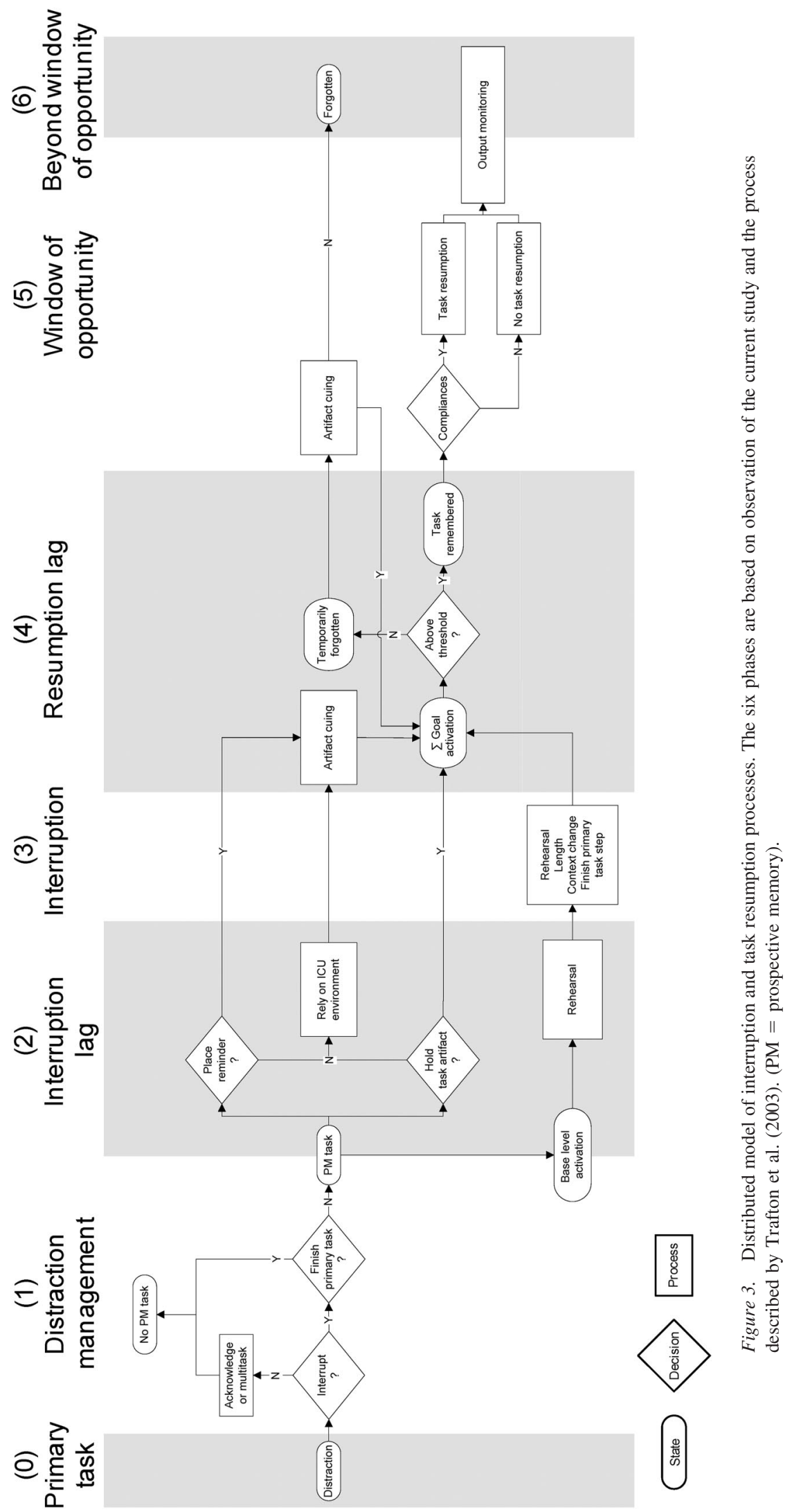


nurse's memory as described by the individual models (base-level or baseline activation). In parallel, nurses made two decisions: whether to place a reminder into the environment and whether to hold an artifact associated with the primary task.

First, to enhance the environment, nurses might place a reminder of the primary task in the environment, such as a medication vial. This kind of strategy is frequently reported in studies of everyday prospective memory tasks (Gould, McDonald-Miszczak, \& King, 1997; Maylor, 1990). However, interruptions often start abruptly and may not leave time for such a time-consuming strategy, which may explain why only three instances were observed (1.7\% of all interruptions).

Second, nurses might decide to hold an artifact relating to the primary task while attending the interruption (18.8\% of all interruptions). Holding a task artifact ensures remembering of the interrupted task. This interpretation is in line with laboratory studies that show that obvious reminders during a delay dramatically increase prospective memory recall (McDaniel et al., 2004). Cognition becomes distributed over time because taking the artifact in the hand before attending to the interruption changes the cognitive demands of how to resume the task. Cognition is also distributed externally because the artifact becomes an additional task representation (Clark \& Chalmers, 1998; Hutchins, 1995b). It is important that holding the artifact changes the memory demands of the task; the monitoring and the content component of the task no longer depend on the individual nurse because the nurse does not need to monitor when to resume which task.

Our results indicated that the decision to hold an artifact was not associated with the actual length of the interruption and therefore interruption length might not have influenced this decision. However, nurses held an artifact more frequently when medication tasks and cleaning tasks were interrupted and less frequently when documentation tasks were interrupted. This indicates that properties of the interrupted task influenced the decision to hold an artifact or not. Documentation tasks were mostly computer-based and therefore did not afford a similar manual strategy. In contrast, medication tasks and cleaning task are manual tasks that are likely to involve artifacts that can be held in the hand.

Furthermore, the distributed model includes two processes during the interruption lag. As the individual models indicate, nurses might engage in active rehearsal of the prospective memory task during the interruption lag. The regression models suggest that nurses did not rehearse at all, because none of the three predictors mediated by rehearsal were significant: interruption lag, distraction during interruption, and fixation on task representation. However, nurses still managed to resume primary tasks after interruptions. Accordingly, we included the process rely on the ICU environment to explain task resumption that depends solely on existing external representations of the tasks. Nurses may rely on encountering a cue in the environment to resume the task. This explanation is supported by the fact that the ICU is a visually rich environment with many cues that might be associated with the task and also by the fact that approximately $75 \%$ of the interrupted primary tasks have a representation in the electronic patient record used in the ICU (see Table 2). Encountering task representations in the system at some point is therefore likely. In Dobbs and Reeves' terms (1996), nurses use their metaknowledge about the availability of cues (task representations available) and do not primarily engage in monitoring (rehearsal of intentions).
A similar strategy was observed for patient assessment. Eight nurses first assessed the patient and then entered the data in the electronic patient record using the available template (one assessment did not get recorded and one assessment was assisted by another nurse). Nurses used the patient record to cue the parameters collected, so changing the task demands from free recall to an item-specific cued recall. In 14 instances, nurses were reminded by the system to check on a parameter that was skipped during the initial assessment.

Phase (3) - Interruption. The characteristics of the interruption itself influence the resumption lag of the interruption. The length of the interruption had a significant effect in the current study (except for interruptions caused by equipment) as did whether the interruption required a context change. In addition, if the nurse finished a primary task step before attending an interruption, task resumption of computer-based documentation tasks was faster. Again, rehearsal of the intention could have an effect if a nurse would prefer this strategy.

Phase (4) - Resumption lag. The resumption lag starts with the end of the interrupting task. As the individual model describes, the goal activation of the primary task representation needs to reach some threshold for the task to be remembered. Goal activation is determined by (1) the activation received during the interruption period as described by the individual model (associative/ source activation); (2) whether a task artifact is held in the hand (Hold task artifact); and (3) whether a nurse encounters a preexisting cue or a placed reminder that will cue the task (Artifact cuing). Holding a task artifact will always push goal activation above the threshold, whereas cuing via deliberately placed reminders and existing artifacts in the ICU environment always depends on encountering one of these cues during the resumption lag.

Phase (5) - Window of opportunity. The window of opportunity represents the time span during which the task can be executed without compromising other tasks or goals. During the window of opportunity, a nurse needs to comply to do the task (Dobbs \& Reeves, 1996). Furthermore, if a cue associated with a temporarily forgotten task is encountered during this phase a safe execution is still possible.

Although we observed only five instances of temporary forgetting, those cases are very informative about task resumption. First, nurses were apparently cued by the environment to resume the tasks, rather than remembering actively. The average resumption lag of almost 10 minutes, the execution of other tasks during the resumption time, and the availability of task representations all support this interpretation. This interpretation is also supported by previous research. Individuals think more often about prospective memory tasks because of external cuing rather than by conscious remembering (Kvavilashvili \& Fisher, 2007). In a further study, most anesthesiologists looked at a blood bag label before remembering a missed blood transfusion beside check, indicating that the label cued memory (Grundgeiger et al., 2008). Second, the five cases in question support the results of the regression model. In all cases, the interruption was very long (twice the average length of the interruptions included in the model) and it included a context change. The decay of activation over time, missing context information at the end of the interruption, and the lack of a specific reminder seemed to prevent retrieval of the intention.

For remembering future tasks, nurses appeared to use general output monitoring strategies that also potentially helped them 
resume forgotten interrupted tasks. First, nurses frequently looked at places where task objects potentially representing uncompleted tasks were located. Second, nurses used cognitively undemanding time, such as when washing hands, to scan the top end of the bed to check on medication in use, ventilator settings, and so on. Similarly, office workers were more likely to think about prospective memory tasks during cognitively undemanding times (Sellen, Louie, Harris, \& Wilkins, 1997). Third, all nurses used the clinical information system, which incorporates a temporally ordered work list that includes nursing tasks and medication tasks (75.8\% of all interrupted primary tasks). All tasks need to be signed when executed or commented on if not executed. The three output monitoring strategies change the nature of prospective memory tasks so that cognition is distributed in various ways. For example, the work list can be seen as a reminder system that has been implemented earlier (distributed over time) and that is used by multiple people (distributed socially).

Phase (6) - Beyond window of opportunity. A cue after the window of opportunity has passed might remind the nurse of a forgotten task, but a timely task execution is no longer possible.

In summary, we observed that nurses react adaptively to the prospective memory demands of interruptions. In visually rich environments, such as the ICU, nurses may trade off the individual cognitive work of encoding or rehearsing and the more distributed cognitive work of relying on external cues to prompt task resumption. It is important to note that the task demands are very different across the two options. If resuming an interruption is not supported, the individual's prospective memory is challenged (Dodhia \& Dismukes, 2009; Trafton et al., 2003); however nurses adapt to these challenges and distribute prospective memory processes into the environment. The distributed model in Figure 3 presents a way to show the interplay between internal and external cognitive processes and the resulting change of the initial prospective memory demand. We argue that nurses' adaptations help to prevent forgetting of tasks due to interruptions. This interpretation is supported by our findings for the recovery of temporarily forgotten interruptions and is consistent with observational studies on memory aids and reminders in hospital settings (Ebright, Patterson, Chalko, \& Render, 2003; Xiao, Milgram, \& Doyle, 1997) and aviation (Hutchins, 1995b).

\section{Limitations}

Our study has several limitations, possibly limiting its generality. First, recording was limited to the period from 7:00 a.m. to 11:00 a.m. Mornings are usually busier and are an ideal environment for studying interruptions; however, other work periods may pose different patterns of interruptions and may produce different strategies of dealing with them. For example, in other models of interruption management, different interruption handling strategies are suggested (Brixey et al., 2007; McFarlane, 2002). Second, the nurse-patient ratio was 1:1 in the ICU under study. In hospital units where nurse-patient ratios range from $1: 2$ to $1: 5$ there may be different interruption patterns, influences of predictors, and behavioral strategies (for the influence of geographical locations on interruptions see, e.g., Ebright et al., 2003). Third, the ICU under study has an electronic patient record which may encourage a distributed remembering process due to the comprehensiveness and accessibility of information, but which may also decrease the need for nurses to create their own reminders. Fourth, eye fixations do not necessarily indicate that the individual is attending to the object fixated. However, humans seldom show task irrelevant fixations in everyday tasks (Findlay \& Gilchrist, 2003; Land, Mennie, \& Rusted, 1999) and fixations are well correlated with attention (Hayhoe \& Ballard, 2005; Just \& Carpenter, 1976).

The field context makes it challenging to control or capture confounding variables, which gives rise to a further class of potential limitations. First, participating nurses were from one ICU only. Our results may not generalize to other ICUs.

Second, task demands of the interrupting task-and specifically the opportunity to rehearse the goal of resuming the task-are known to affect resumption lags (Monk et al., 2008). We were not able to judge the task demand of an interrupting task in these terms. However, in our more detailed analyses we sought any differences due to the source of the interruption and found that the predictors were largely unchanged. Furthermore, it is unlikely that task demand would have had an effect because nurses did not seem to engage in goal rehearsal. This is indicated by the fact that no predictor mediated by rehearsal (interruption lag, distractions during interruptions, and fixation on task representation) had an effect on resumption times and other research that showed that in field settings individuals seldom rehearse intentions (Einstein \& McDaniel, 2007; Dismukes \& Nowinski, 2007; Kvavilashvili \& Fisher, 2007).

Third, emphasizing the importance of the prospective memory task has been shown to improve performance because participants will allocate more resources to strategic monitoring processes (Kliegel, Martin, McDaniel, \& Einstein, 2004). Although we cannot exclude the possibility that task importance had an effect, the fact that all tasks were daily nursing tasks without an emergency and the low probability of explicit rehearsal of goals make an effect of task importance unlikely.

Fourth, the current study and the laboratory-based models do not consider possible interference from the interrupting task on people's intention to recall the primary task. For example, when interference is seen as an inhibitory control mechanism (Anderson, 2003), an interrupting task very similar to the primary task (e.g., a medication preparation is interrupted by another nurse for a medication check) might inhibit the task representation of the primary task, which would make task resumption more difficult.

Fifth, in contrast to tasks in laboratory studies, the primary tasks in the ICU are not novel to participants but instead have been frequently executed. Although laboratory studies have not found an effect of brief primary task practice on the resumption lag (Cades, Trafton, \& Boehm-Davis, 2006), in the ICU the extensive repetition of exactly the same tasks (e.g., patient assessment) compared to others (e.g., conversations) might have an effect on resumption lag. The literature on habit formation supports this argument, as extensively repeated actions are automatically cued by context cues without much cognitive effort (Neal, Wood, \& Quinn, 2006).

\section{Future Research}

Future research in controlled laboratory or simulator settings is needed to investigate whether the possibly confounding factors in the current study and other factors raised by the current study do 
affect resumption times. Furthermore, both the memory for goals model and the associative activation model are rather vague about the mechanisms of context change but researchers have started to investigate those mechanisms (Marsh, Hicks, \& Cook, 2008). The strong effect of context in the main model $\left(\mathrm{s} r^{2}=.339\right)$ and the significant effect of context change in all submodels warrants further research. One mechanism involved in the context effect might be spatial memory. Recently, Ratwani and Trafton (2008) investigated the contribution of spatial memory to task resumption times and observed that interruptions that demand spatial processing are more disruptive. In the present study, the change in location might have made encoded spatial information invalid for task resumption.

Further research in the field is needed to get a fuller picture of the behaviors that influence memory demands. The distributed model gives a first insight into factors that influence decisions about how to handle an initial distraction or whether to finish a primary task. Further research is needed on factors that influence these decisions, such as the properties of the distracting task or primary task, or the cognitive demands of a possible prospective memory task (Gray \& Fu, 2004).

Because practical and ethical constraints limit the control of events in field studies, patient simulators might provide a powerful tool for developing and testing rich theories of context-conditioned human activity, such as theories informed by distributed cognition. Simulators let participants use their prior experience and familiar physical artifacts, yet researchers can exert more control than is possible in the field. Simulators might also make it possible to investigate more specific task resumption points, rather than simply whether a task was resumed at all as is the case in the current study.

\section{Implications for Intensive Care Settings}

A straightforward approach to prevent cognitive disruptions caused by interruptions is to prevent interruptions from happening. This might be a solution for certain tasks such as medication rounds (Pape et al., 2005), but it is not a practical solution for all situations because interruptions are an important way to communicate critical information in a timely fashion (Coiera \& Tombs, 1998).

The approach advocated here is to understand the mechanisms that make interruptions disruptive and try to prevent or ease the disruptiveness while retaining the benefits of interruptions (Grundgeiger \& Sanderson, 2009). First, based on the interruption length effect, keeping the interruption shorter is likely to lower the cognitive effort in resuming the interrupted task. Second, interruptions that include a context change have been more disruptive. Therefore, resolving the interruptions "on the spot" rather than leaving the current location could ease task resumption. Third, for computer-based documentation tasks, finishing a primary task step before attending the interruption might also benefit task resumption. Fourth, staff can be educated about the use of behavioral strategies to prevent individual prospective memory tasks, such as intentionally finishing a task before attending an interruption or, if possible, holding task artifacts in the hands prevent any demand on the individual nurse. This is particularly relevant now that interruption management strategies are introduced during simulatorbased training (Fox-Robichaud \& Nimmo, 2007). Furthermore, the distribution of memory demands over time, externally, or socially (Hutchins, 1995a) might lower the dependency on individual cognition and potentially make task execution more likely. Fifth, designers of hospital equipment and physical environments might find ways to make tasks visible through such means as persistent status flags. Nurses apparently use strategies that use the environment for resuming interrupted tasks and for supporting prospective memory tasks in general. Visible tasks will increase the chance of incidental cuing and therefore the chance of resuming temporarily forgotten tasks.

\section{Conclusion}

This paper presents a prospective, theoretically guided, field investigation of interruptions in health care. The resumption lag measurement was used as an indicator of how easily the interrupted primary task can be recalled. The overall regression model revealed that longer interruptions and a change in the nurse's location hamper task resumption. In addition, the regression submodels indicated that finishing a primary task step before attending an interruption eases the resumption of computer-based documentation tasks and that the resumption is unaffected by the interruption length when the interruption is caused by equipment. In general, the memory for goals theory (Altman \& Trafton, 2002; Trafton et al., 2003) accommodates the results better than the associative activation model (Dismukes \& Nowinski, 2007). However, the individual models of task resumption only accounted for $55.8 \%$ of all interruptions because of nurses' behavioral strategies, indicating that theories based on laboratory experiments miss factors that influence how people respond to interruptions in a work domain such as intensive care nursing.

We found that nurses frequently used strategies that distribute memory demands into the immediate environment and therefore diminish or prevent demands on individual cognition. The field context revealed factors and situations such as holding a task artifact while attending an interruption, which led to immediate task resumption without cognitive effort for an individual. The results relating to the behavioral strategies show that it is necessary to extend research beyond the individual mind and include the adaptive and discretionary use of artifacts and other forms of distributed cognition to understand the management and effects of interruptions. The descriptive distributed model proposed herein is a first step to incorporate internal and external processes and to describe their interplay. The model can be used to investigate interruptions and prospective memory in other health care settings or other domains and to evaluate the risk of forgetting tasks by estimating the distributed nature of the task.

\section{References}

Altmann, E. M., \& Trafton, J. G. (2002). Memory for goals: An activationbased model. Cognitive Science, 26, 39-83.

Anderson, J. R., \& Lebiere, C. (1998). Atomic components of thought. Mahwah, NJ: Erlbaum.

Anderson, M. C. (2003). Rethinking interference theory: Executive control and the mechanisms of forgetting. Journal of Memory and Language, 49, 415-445.

Bakeman, R., \& Gottman, J. M. (1997). Observing interaction: An introduction to sequential analysis. New York: Cambridge University Press. Biron, A. D., Loiselle, C. G., \& Lavoie-Tremblay, M. (2009). Work 
interruptions and their contribution to medication administration errors: An evidence review. Worldviews on Evidence-Based Nursing, 6, 70-86.

Brandimonte, M., Einstein, G. O., \& McDaniel, M. A. (Eds.). (1996). Prospective memory: Theory and applications. Mahwah, NJ: L. Erlbaum.

Brixey, J. J., Robinson, D. J., Johnson, C. W., Johnson, T. R., Turley, J. P., \& Zhang, J. (2007). A concept analysis of the phenomenon interruption. Advances in Nursing Science, 30, E26-E42.

Cades, D. M., Trafton, J. G., \& Boehm-Davis, D. A. (2006, October). Mitigating disruptions: Can resuming an interrupted task be trained? Paper presented at the Human Factors and Ergonomics Society 50th Annual Meeting, San Francisco.

Cades, D. M., Trafton, J. G., Boehm-Davis, D. A., \& Monk, C. A. (2007, October). Does the difficulty of an interruption affect our ability to resume? Paper presented at the 51st Annual Meeting of the Human Factors and Ergonomics Society, Santa Monica, CA.

Cherry, K. E., Martin, R. C., Simmons-D'Gerolamo, S. S., Pinkston, J. B., Griffing, A., \& Gouvier, D. (2001). Prospective remembering in younger and older adults: Role of the prospective cue. Memory, 9, 177-193.

Chisholm, C. D., Collison, E. K., Nelson, D. R., \& Cordell, W. H. (2000). Emergency department workplace interruptions: Are emergency physicians "interrupt-driven" and "multitasking"? Academic Emergency Medicine, 7, 1239-1243.

Clark, A., \& Chalmers, D. (1998). The extended mind (Active externalism). Analysis, 58, 7-19.

Coiera, E. W., \& Tombs, V. (1998). Communication behaviours in a hospital setting: An observational study. British Medical Journal, 316, 673-676.

Collins, S. A., Currie, L., Patel, V. L., Bakken, S., \& Cimino, J. J. (2007). Multitasking by clinicians in the context of CPOE and CIS use. MedInfo 2007, Proceedings of the 12th World Congress on Health (Medical) Informatics, Brisbane, Australia.

Dismukes, R. K. (2008). Prospective memory in aviation and everyday settings. In M. Kliegel, M. A. McDaniel, \& G. O. Einstein (Eds.), Prospective memory: Cognitive, neuroscience, developmental, and applied perspectives (pp. 411-431). New York: Erlbaum.

Dismukes, R. K., \& Nowinski, J. (2007). Prospective memory, concurrent task management, and pilot error. In A. Kramer, D. Wiegmann, \& A. Kirlik (Eds.), Attention: From theory to practice (pp. 225-236). New York: Oxford.

Dismukes, R. K., Young, G. E., \& Sumwalt, R. L. (1998). Cockpit interruptions and distractions: Effective management requires a careful balancing act. ASRS Directline, 10, 4-9.

Dobbs, A. R., \& Reeves, B. (1996). Prospective memory: More than memory. In M. Brandimonte, G. O. Einstein, \& M. A. McDaniel (Eds.), Prospective memory: Theory and applications (pp. 199-225). Mahwah, NJ: L. Erlbaum.

Dodhia, R. M., \& Dismukes, R. K. (2009). Interruptions create prospective memory tasks. Applied Cognitive Psychology, 23, 73-89.

Ebright, P. R., Patterson, E. S., Chalko, B. A., \& Render, M. L. (2003). Understanding the complexity of registered nurse work in acute care settings. Journal of Nursing Administration, 33(12), 630-638.

Einstein, G. O., \& McDaniel, M. A. (1990). Normal aging and prospective memory. Journal of Experimental Psychology-Learning Memory \& Cognition, 16, 717-726.

Einstein, G. O., \& McDaniel, M. A. (1996). Retrieval processes in prospective memory: Theoretical approaches and some new empirical findings. In M. Brandimonte, G. O. Einstein, \& M. A. McDaniel (Eds.), Prospective memory: Theory and applications (pp. 115-142). Mahwah, NJ: Erlbaum.

Einstein, G. O., \& McDaniel, M. A. (2007). Prospective memory and metamemory: The skilled use of basic attentional and memory processes. In A. S. Benjamin \& B. H. Ross (Eds.), Psychology of Learning and Motivation - Advances in Research and Theory (Vol. 48, pp. 145-173).

Einstein, G. O., McDaniel, M. A., Williford, C. L., Pagan, J. L., \& Dismukes, R. K. (2003). Forgetting of intentions in demanding situations is rapid. Journal of Experimental Psychology Applied, 9, 147-162.

Einstein, G. O., Smith, R. E., McDaniel, M. A., \& Shaw, P. (1997). Aging and prospective memory: The influence of increased task demands at encoding and retrieval. Psychology and Aging, 12, 479-488.

Ellis, J. (1996). Prospective memory or the realization of delayed intentions: A conceptual framework for research. In M. Brandimonte, G. O. Einstein, \& M. A. McDaniel (Eds.), Prospective memory: Theory and applications (pp. 1-51). Mahwah, NJ: L. Erlbaum.

Findlay, J., \& Gilchrist, I. (2003). Active vision: The psychology of looking and seeing. Oxford: Oxford University Press.

Fioratou, E., Flin, F., Glavin, R., \& Patey, R. (2010). Beyond monitoring: Distributed situation awareness in anaesthesia. British Journal of Anaesthesia, 105, 83-90.

Fox-Robichaud, A. E., \& Nimmo, G. R. (2007). Education and simulation techniques for improving reliability of care. Current Opinion in Critical Care, 13, 737-741.

Gould, O. N., McDonald-Miszczak, L., \& King, B. (1997). Metacognition and medication adherence: How do older adults remember? Experimental Aging Research, 23, 315-342.

Gray, W. D., \& Fu, W. T. (2004). Soft constraints in interactive behavior: The case of ignoring perfect knowledge in-the-world for imperfect knowledge in-the-head. Cognitive Science, 28, 359-382.

Grundgeiger, T., Liu, D., Sanderson, P., Jenkins, S., \& Leane, T. (2008, September). Effects of interruptions on prospective memory performance in anesthesiology. Paper presented at the 52nd Annual Meeting of the Human Factors and Ergonomics Society, New York.

Grundgeiger, T., \& Sanderson, P. (2009). Interruptions in healthcare: Theoretical views. International Journal of Medical Informatics, 293307.

Grundgeiger, T., Sanderson, P. M., Beltran Orihuela, C., Thompson, A., MacDougall, H. G., Nunnink, L., \& Venkatesh, B. (2010, October). Distractions and interruptions in the intensive care unit: Field observation and a controlled simulator experiment. Paper accepted for the 54th Annual Meeting of the Human Factors and Ergonomics Society, San Francisco.

Grundgeiger, T., Sanderson, P. M., MacDougall, H. G., \& Venkatesh, B. (2009a, October). Distributed prospective memory: An approach to understanding how nurses remember tasks. Paper presented at the 53rd Annual Meeting of the Human Factors and Ergonomics Society, San Antonio, TX.

Grundgeiger, T., Sanderson, P. M., MacDougall, H. G., \& Venkatesh, B. (2009b, August). How nurses overcome interruptions: An analysis of distributed support. Paper presented at the 17th World Congress on Ergonomics, Beijing, China.

Hayhoe, M., \& Ballard, D. (2005). Eye movements in natural behavior. Trends in Cognitive Sciences, 9, 188-194.

Hazlehurst, B., \& McMullen, C. (2007). Orienting frames and private routines: The role of cultural process in critical care safety. International Journal of Medical Informatics, 76, S129-S135.

Hodgetts, H. M., \& Jones, D. M. (2006a). Contextual cues aid recovery from interruption: The role of associative activation. Journal of Experimental Psychology-Learning Memory \& Cognition, 32, 1120-1132.

Hodgetts, H. M., \& Jones, D. M. (2006b). Interruption of the tower of London task: Support for a goal-activation approach. Journal of Experimental Psychology-General, 135, 103-115.

Hollan, J., Hutchins, E., \& Kirsh, D. (2000). Distributed cognition: Toward a new foundation for human-computer interaction research. ACM Transactions on Computer-Human Interaction, 7, 174-196.

Horsky, J., Kaufman, D. R., Oppenheim, M. I., \& Patel, V. L. (2003). A 
framework for analyzing the cognitive complexity of computer-assisted clinical ordering. Journal of Biomedical Informatics, 36, 4-22.

Hutchins, E. (1995a). Cognition in the wild. Cambridge, MA: MIT Press. Hutchins, E. (1995b). How a cockpit remembers its speeds. Cognitive Science, 19, 265-288.

Hutchins, E. (2001). Distributed cognition. In J. S. Neil \& B. B. Paul (Eds.), The international encyclopedia of the social and behavioral sciences (pp. 2068-2072). Oxford: Pergamon Press.

Iqbal, S. T., \& Horvitz, E. (2007, May). Disruption and recovery of computing tasks: Field study, analysis, and directions. Paper presented at the Proceedings of CHI 2007.

Just, M. A., \& Carpenter, P. A. (1976). Eye fixations and cognitive processes. Cognitive Psychology, 8, 441-480.

Kliegel, M., Martin, M., McDaniel, M. A., \& Einstein, G. O. (2004). Importance effects on performance in event-based prospective memory tasks. Memory, 12, 553-561.

Kliegel, M., McDaniel, M. A., \& Einstein, G. O. (2008). Prospective memory: Cognitive, neuroscience, developmental, and applied perspectives. New York: Erlbaum.

Koriat, A., Benzur, H., \& Sheffer, D. (1988). Telling the same story twiceoutput monitoring and age. Journal of Memory and Language, 27, 23-39.

Kvavilashvili, L., \& Fisher, L. (2007). Is time-based prospective remembering mediated by self-initiated rehearsals? Role of incidental cues, ongoing activity, age, and motivation. Journal of Experimental Psychology-General, 136, 112-132.

Land, M., Mennie, N., \& Rusted, J. (1999). The roles of vision and eye movements in the control of activities of daily living. Perception, 28, 1311-1328.

Liu, D., Grundgeiger, T., Sanderson, P. M., Jenkins, S., \& Leane, T. (2009). Interruptions and blood transfusion checks: Lessons from the simulated operating room. Anesthesia and Analgesia, 108, 219-222.

MacDougall, H. G., \& Moore, S. T. (2005). Functional assessment of head-eye coordination during vehicle operation. Optometry and Vision Science, 82, 706-715.

MacDougall, H. G., Weber, K. P., McGarvie, L. A., Halmagyi, G. M., \& Curthoys, I. S. (2009). The video head impulse test Diagnostic accuracy in peripheral vestibulopathy. Neurology, 73, 1134-1141.

Marsh, R. L., Hicks, J. L., \& Cook, G. I. (2006). Task interference from prospective memories covaries with contextual associations of fulfilling them. Memory \& Cognition, 34, 1037-1045.

Marsh, R. L., Hicks, J. L., \& Cook, G. I. (2008). On beginning to understand the role of context in prospective memory. In M. Kliegel, M. A. McDaniel, \& G. O. Einstein (Eds.), Prospective memory: Cognitive, neuroscience, developmental, and applied perspectives (pp. 77100). New York: Erlbaum.

Marsh, R. L., Hicks, J. L., \& Landau, J. D. (1998). An investigation of everyday prospective memory. Memory \& Cognition, 26, 633-643.

Maylor, E. A. (1990). Age and prospective memory. Quarterly Journal of Experimental Psychology Section a-Human Experimental Psychology, 42, 471-493.

McDaniel, M. A., \& Einstein, G. O. (2000). Strategic and automatic processes in prospective memory retrieval: A multiprocess framework. Applied Cognitive Psychology, 14, 127-144.

McDaniel, M. A., \& Einstein, G. O. (2007). Prospective Memory: An overview and synthesis of an emerging field. Thousand Oaks, CA: Sage.

McDaniel, M. A., Einstein, G. O., Graham, T., \& Rall, E. (2004). Delaying execution of intentions: Overcoming the costs of interruptions. Applied Cognitive Psychology, 18, 533-547.

McDaniel, M. A., Einstein, G. O., Stout, A. C., \& Morgan, Z. (2003). Aging and maintaining intentions over delays: Do it or lose it. Psychology and Aging, 18, 823-835.

McFarlane, D. C. (2002). Comparison of four primary methods for coordinating the interruption of people in human-computer interaction. Human-Computer Interaction, 17, 63-139.
McGann, D., Ellis, J. A., \& Milne, A. (2002). Conceptual and perceptual processes in prospective remembering: Differential influence of attentional resources. Memory \& Cognition, 30, 1021-1032.

Meacham, J. A., \& Leiman, B. (1982). Remembering to perform future actions. In U. Neisser (Ed.), Memory observed (pp. 327-336). San Francisco: Freeman.

Monk, C. A., Boehm-Davis, D. A., \& Trafton, J. G. (2004). Recovering from interruptions: Implications for driver distraction research. Human Factors, 46, 650-663.

Monk, C. A., Trafton, J. G., \& Boehm-Davis, D. A. (2008). The effect of interruption duration and demand on resuming suspended goals. Journal of Experimental Psychology-Applied, 14, 299-313.

Monsell, S. (2003). Task switching. Trends in Cognitive Sciences, 7 , $134-140$.

Moore, S. T., Haslwanter, T., Curthoys, I. S., \& Smith, S. T. (1996). A geometric basis for measurement of three-dimensional eye position using image processing. Vision Research, 36, 445-459.

Neal, D. T., Wood, W., \& Quinn, J. M. (2006). Habits- A repeat performance. Current Directions in Psychological Science, 15, 198-202.

Neisser, U. (1976). Cognition and reality: Principles and implications for cognitive psychology. New York: Freeman and Company.

Nemeth, C. P., Cook, R. I., O'Connor, M. F., \& Klock, P. A. (2004). Using cognitive artifacts to understand distributed cognition. IEEE Transactions on Systems, Man and Cybernetics Part A: Systems and Humans, $34,726-735$.

Norman, D. A. (1991). Cognitive artifacts. In J. M. Carroll (Ed.), Designing interaction psychology at the human-computer interface (pp. 17-38). Cambridge: Cambridge University Press.

Nowinski, J., \& Dismukes, R. K. (2005). Effects of ongoing task context and target typicality on prospective memory performance: The importance of associative cueing. Memory, 13, 649-657.

Omodei, M. M., McLennan, J. P., \& Wearing, A. J. (2005). How expertise is applied in real-world dynamic environments: Head mounted video and cued recall as a methodology for studying routines of decision making. In T. Betsch \& S. Haberstroh (Eds.), The routines of decision making (pp. 271-288). Mahwah, N. J.: Erlbaum.

Pape, T. M., Guerra, D. M., Muzquiz, M., Bryant, J. B., Ingram, M., Schranner, B., ... Welker, J. (2005). Innovative approaches to reducing nurses' distractions during medication administration. The Journal of Continuing Education in Nursing, 36, 108-116.

Parker, J., \& Coiera, E. (2000). Improving clinical communication: A view from psychology. Journal of the American Medical Informatics Association, 7, 453-461.

Ratwani, R. M., \& Trafton, J. G. (2008). Spatial memory guides task resumption. Visual Cognition, 16, 1001-1010.

Raudenbush, S. W., \& Bryk, A. S. (2002). Hierarchical linear models: Applications and data analysis methods. Thousand Oaks, CA: Sage.

Salthouse, T. A., \& Ellis, C. L. (1980). Determinants of eye-fixation duration. American Journal of Psychology, 93, 207-234.

Sellen, A. J., Louie, G., Harris, J. E., \& Wilkins, A. J. (1997). What brings intentions to mind? An in situ study of prospective memory. Memory, 5, $483-507$.

Smith, R. E. (2003). The cost of remembering to remember in event-based prospective memory: Investigating the capacity demands of delayed intention performance. Journal of Experimental Psychology-Learning Memory \& Cognition, 29, 347-361.

Strayer, D. L., \& Johnston, W. A. (2001). Driven to distraction: Dual-task studies of simulated driving and conversing on a cellular telephone. Psychological Science, 12, 462-466.

Suchman, L. A. (1987). Plans and situated actions: The problem of humanmachine communication. New York: Cambridge University Press.

Torpy, J. M., Lynm, C., \& Glass, R. M. (2009). Intensive care units. The Journal of the American Medical Association, 301, 1304.

Trafton, J. G., Altmann, E. M., \& Brock, D. P. (2005). Huh, what was I 
doing? How people use environmental cues after an interruption. The Proceedings of the Human Factors and Ergonomics Society 49th Annual Meeting. Santa Monica, CA: Human Factors and Ergonomics Society.

Trafton, J. G., Altmann, E. M., Brock, D. P., \& Mintz, F. E. (2003). Preparing to resume an interrupted task: Effects of prospective goal encoding and retrospective rehearsal. International Journal of HumanComputer Studies, 58, 583-603.

Trafton, J. G., \& Monk, C. A. (2007). Task interruptions. Reviews of Human Factors and Ergonomics, 3, 111-126.

Tulving, E., \& Thomson, D. M. (1973). Encoding specificity and retrieval processes in episodic memory. Psychological Review, 80, 352-373.

Westbrook, J. I., Coiera, E., Dunsmuir, W. T. M., Brown, B. M., Kelk, N., Paoloni, R., \& Tran, C. (2010a). The impact of interruptions on clinical task completion. Quality and Safety in Health Care, 19(4), 284-289.

Westbrook, J. I., Woods, A., Rob, M. I., Dunsmuir, W. T. M., \& Day, R. O. (2010b). Association of interruptions with an increased risk and severity of medication administration errors. Archives of Internal Medicine, 170, 683-690.
Xiao, Y. (2005). Artifacts and collaborative work in healthcare: Methodological, theoretical, and technological implications of the tangible. Journal of Biomedical Informatics, 38, 26-33.

Xiao, Y., Milgram, P., \& Doyle, D. J. (1997). Planning behavior and its functional role in interactions with complex systems. IEEE Transactions on Systems, Man, and Cybernetics Part A: Systems and Humans, 27, 313-324.

Zhang, J. J., \& Norman, D. A. (1994). Representations in distributed cognitive tasks. Cognitive Science, 18, 87-122.

Zhang, J. J., \& Norman, D. A. (1995). A representational analysis of numeration systems. Cognition, 57, 271-295.

Received April 16, 2009

Revision received August 5, 2010

Accepted September 20, 2010

\section{New Editors Appointed for Journal of Neuroscience, Psychology, and Economics, 2011-2016}

The American Psychological Association is pleased to announce the appointment of new co-editors for Journal of Neuroscience, Psychology, and Economics for a 6-year term beginning in 2011. As of January 1, 2011, all new manuscripts should be directed to:

\section{Daniel Houser, PhD}

George Mason University

Truland Building, Suite 400

3330 Washington Blvd.

Arlington, VA 22201

Bernd Weber, MD

Department of Epileptology, University Hospital Bonn

Head, NeuroCognition/Imaging, Life \& Brain Center

Sigmund-Freud-Str. 25

53127 Bonn

Germany

Electronic manuscript submission: As of January 1, 2011, manuscripts should be submitted electronically to the new editors via the journal's Manuscript Submission Portal: http:// www.apa.org/pubs/journals/npe, under the Instructions to Authors.

Manuscript submission patterns make the precise date of completion of the 2010 volumes uncertain. The current co-editors, Martin Reimann, $\mathrm{PhD}$, and Oliver Schilke, $\mathrm{PhD}$, will receive and consider new manuscripts through December 31, 2010. Should 2010 volumes be completed before that date, manuscripts will be redirected to the new editors for consideration in the 2011 volume. 